\title{
Analysis of Time Diversity Gain for Satellite Communication Link based on Ku-Band Rain Attenuation Data Measured in Malaysia
}

\author{
Islam Md. Rafiqul ${ }^{1}$, Ali Kadhim Lwas ${ }^{2}$, Mohamed Hadi Habaebi ${ }^{3}$, Md Moktarul Alam ${ }^{4}$, Jalel Chebil $^{5}$, \\ Jit Singh Mandeep ${ }^{6}$, Alhareth Zyoud ${ }^{7}$ \\ ${ }^{1,2,3,4,7}$ Department of Electrical and Computer Engineering, Faculty of Engineering, \\ International Islamic University Malaysia, Jalan Gombak, 53100 Kuala Lumpur, Malaysia \\ ${ }^{5}$ Department of Technology and Engineering in Transport, University of Sousse, Tunisia \\ ${ }^{6}$ Faculty of Engineering and Built Environment University Kebangsaan Malaysia, Malaysia
}

\section{Article Info}

Article history:

Received Jan 11, 2018

Revised Apr 2, 2018

Accepted Apr 9, 2018

Keyword:

Earth-satellite links

Rain attenuation

Time diversity gain

\begin{abstract}
This paper reports a study on mitigation of propagation impairments on Earth-space communication links. The study uses time diversity as a technique for mitigating rain propagation impairment in order to rectify rain fade. Rain attenuation time series along earth-to-satellite link were measured for two years period at $12.255 \mathrm{GHz}$ in Malaysia. The time diversity technique was applied on measured rain fade to investigate the level of possible improvement in system. Time diversity gain from measured oneminute rain attenuation for two years period was estimated and significant improvement was observed with different delays of time. These findings will be utilized as a useful tool for link designers to apply time diversity as a rain fade mitigation technique in Earth-satellite communications systems.
\end{abstract}

Copyright $@ 2018$ Institute of Advanced Engineering and Science. All rights reserved.

\section{Corresponding Author:}

Md Rafiqul Islam,

Department of Electrical and Computer Engineering,

Intenational Islamic University Malaysia,

E1 building, Khulliyah of Engineering, IIUM, Gombak 53100, Selangor, Malaysia.

Email: rafiq@iium.edu.my

\section{INTRODUCTION}

Due to the high demands on higher frequency range, the International Telecommunication Union (ITU) released recently a new broadcasting bands operating at 21.4-22 GHz for region 1 and region 3 [1]. Tropical countries such as Malaysia that is located in ITU region 3 experience many of heavy rain events during the year. This will cause a huge attenuation to the satellite signal during the raining events [2]. In order to mitigate the signal degradation, either a large fade margin should be included in the transmission system or a mitigation technique should be applied. It is not a practical way to include a large fade margin in link budget. Thus, using a mitigation technique is more significant to overcome the signal strength degradation.

Several fade mitigation techniques have been proposed in the open literature to handle the signal attenuation during rain in tropical region. Techniques such as power control [3], site diversity [4], [5] frequency diversity [6], [7] and time diversity [8] show a promising result. However, the time diversity technique considered the most attractive in terms of implementation cost and efficiency for non real time satellite applications. The main drawback of time diversity technique is that it is not applicable for real time applications. However, using this technique will significantly eliminate the rain attenuation and compensate the satellite signal. Considering that, the same signal needs to be delivered again in a better channel conditions than the first signal. Therefore, a propagation mid-term prediction model is required to accurately 
determine the best signal condition to deliver the message for the second time. Some studies have been conducted around the world and a few in tropical regions to evaluate the time diversity technique. Some of these studies are based on direct approach for data collected from satellite beacon signal, while other studies are based on indirect approach based on data converted using prediction formula.

In temperate region, the time diversity technique has been evaluated and a statistical time diversity gain model has been proposed at $18.7 \mathrm{GHz}$ [9]. The proposed model is a function of time delay, frequency and rain attenuation. The model was developed based on simulation data extracted using the synthetic storm technique. The proposed time diversity gain model in [10] is based on the lognormal joint probability density function. The Authors assumed that the rain attenuation as a function of time is following the lognormal distribution. Then, a dynamic rain attenuation parameter has been proposed to calculate the time diversity gain at frequencies between 12 to $50 \mathrm{GHz}$. The same data were used in [11] to propose another model based on time correlation of the attenuation Complementary Cumulative Distribution Function (CCDF). The CCDF parameters are found to be dependent on elevation angle and local climatology. Moreover, a new computation method of rain attenuation CCDF based on Maseng-Bakken stochastic dynamic model is presented in [12]. In tropical regions, a prediction model is proposed based on measured satellite beacon signal at $12 \mathrm{GHz}$ in Malaysia; this model leads to find time diversity gain. The proposed empirical formula is a function of time delay [7].

In this paper, the time diversity technique has been evaluated using beacon data obtained via SUPERBIRD-C satellite at University Science Malaysia (Universiti Sains Malaysia), USM in Penang, Malaysia. The measurements are at $12.255 \mathrm{GHz}$ frequency.

\section{TIME DIVERSITY CONCEPT}

In order to make the time diversity technique viable, ground precipitation information for target areas should be available to allow for the determination of attenuation occurrence. Such weather information is collected by ground stations and propagated to participating parties that include gateway and broadcast stations. Sever rain attenuation, detected in target areas, will trigger the application of time diversity in participating gateways. The range of time diversity can vary from 1 minute to more than 1 hour, and the same information is retransmitted.

Time diversity will put processing and memory burdens on the receivers where in some instances a considerable processing time is needed. Memory is also required for storage of received data prior to processing it. The final version of the transmitted information is then assembled by the receiver from the two received sets by combing the clearest segments from each. It is a clear, the technique of time diversity is suitable for applications such as data transfer process that need not until the rain fades before they get the particular information.

The complementary cumulative distribution function of rain attenuation conditioned to the time delay can be used to estimate the performance of time diversity as follows [11]:

$$
P(A)=P\left[A(t)>A_{t h}, A(\delta t)>A_{t h}\right]
$$

$\mathrm{A}(\mathrm{t})$ refers to rain attenuation without time delay, while $\delta \mathrm{t}$ is defined as a time diversity delay and $\mathrm{A}(\delta \mathrm{t})$ refers to rain attenuation shifted of $\delta \mathrm{t}$. Also, Ath is defined as an attenuation threshold on the used link.

Equation (1) can be re-written as follows:

$$
P(A)=P\left[\min \left(A(t)>A_{t h}, A(\delta t)>A_{t h}\right)\right]
$$

This represents the time of percentage exceeded for minimal rain attenuation. Therefore, the signal of satellite to earth will be subjected to minimal rain attenuation as a result of using time diversity technique and is expressed by the model.

$$
A_{T D}=\min [A(t), A(\delta t)]
$$

There is a need to make a comparison of the original time series of attenuation and the same time series delay by given time interval in order to get the lowest attenuation value as explained in Equation (2). An illustrative example for the use of time delay technique is presented in Figure 1. An event of measured signal on the satellite-Earth link is applied. It is clear that the maximum attenuation of the signal without time 
delay is about $28.24 \mathrm{~dB}$, but after applying time diversity technique with time delay of 10 and $30 \mathrm{~min}$, the maximum rain attenuation is 24.35 and $7 \mathrm{~dB}$ respectively.
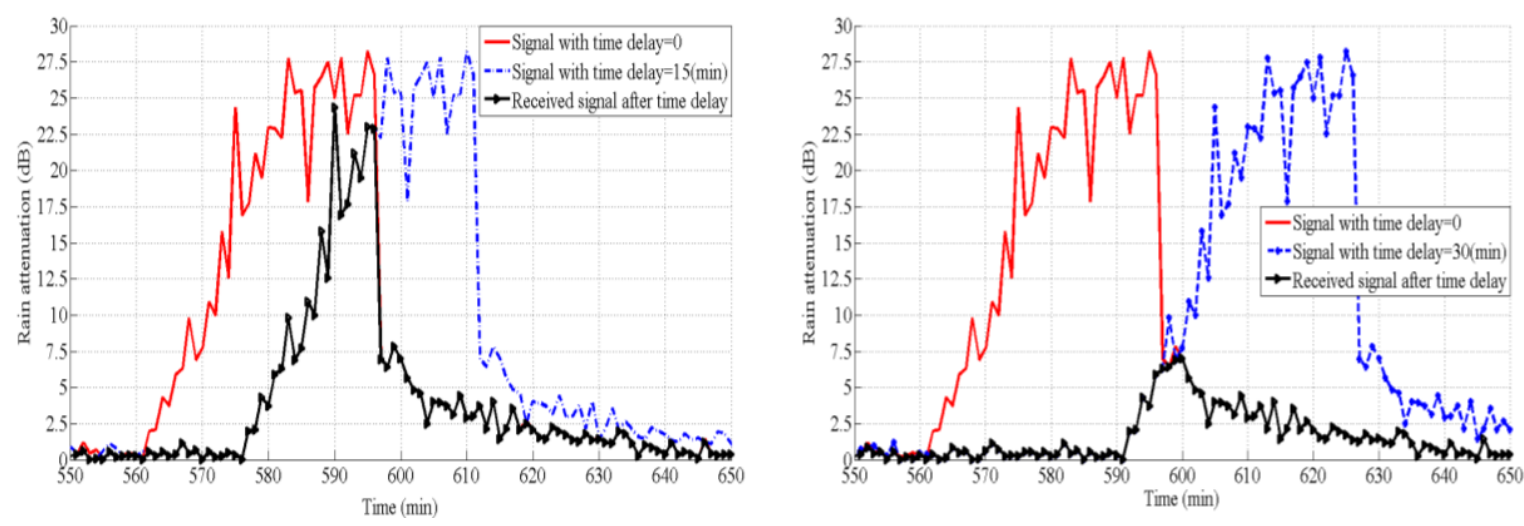

Figure 1. An Example, which illustrates the use of time diversity technique in the signal of a satellite-Earth link for an event, measured at Penang-Malaysia on 9/8/2009.

Time diversity gain is the value of the difference in $\mathrm{dB}$ between the cumulative distributions of rain attenuation of the communication signal and the same signal with defined time delay. Therefore, the time diversity gain is used to evaluate the time diversity as a fade mitigation technique for rain attenuation. Time diversity gain can be expressed statistically by the following equation.

$$
G_{T D}=A(t)-A_{T D}
$$

where $G_{T D}$ is time diversity gain.

\section{DATA COLLECTION}

The receiver is located at University Science Malaysia (Universiti Sains Malaysia), USM (4.39 ${ }^{\circ}$, $100.98^{\circ} \mathrm{E}$ ) at a height above mean sea level of $57 \mathrm{~m}$ for receiving beacon measurement of the signal. The signal from the SUPERBIRD-C satellite transmitted at $12.255 \mathrm{GHz}$ and an elevation angle of $40.1^{\circ}$ was received. The size of antenna dish was $2.4 \mathrm{~m}$ and the low-noise block (LNB) was connected with the antenna to convert the ku-band to an intermediate frequency. The output of the LNB was connected to the indoor unit to process the signal for display. Readings were displayed by a personal computer, which was programmed to read the data in every second and average over one minute. The data were collected for 2 years over the period of 2008 and 2009. The average data availability was over $96 \%$.

\section{TIME DIVERSITY ESTIMATION}

The marginal distribution has a probability function or density function. Therefore, it can be found by the complementary conventional cumulative probability distribution function of the percentages of the exceeded value. The complementary cumulative distribution of rain attenuation time series for a satellite to earth link can be expressed as follows:

$$
P(A)=P[A(t)>A]=\int_{A}^{\infty} \psi[A(t)] d A(t)
$$

where $\psi(\mathrm{A})$ refers to the density function of rain attenuation and $\mathrm{P}(\mathrm{A})$ refers to its integral. The joint distribution for $\mathrm{A}(\mathrm{t})$ and $\mathrm{A}(\delta \mathrm{t})$ is given by. 


$$
P[A(t)>A, A(\delta t)>A]=\int_{A}^{\infty} \int_{A}^{\infty} \gamma[A(t), A(\delta t)] d A(t) d A(\delta t)
$$

where $\gamma[\mathrm{A}(\mathrm{t}), \mathrm{A}(\delta \mathrm{t})]$ represents the joint probability density function.

Figure 2 and Figure 3 represent an example for Equations (5) and (6).The satellite signal is used to implement time diversity as a rain fade mitigation technique. Figure 2 and Figure 3 show considerable decrease in the attenuation for the same probability of exceedance as they illustrate the complementary cumulative distribution function of the rain attenuation.

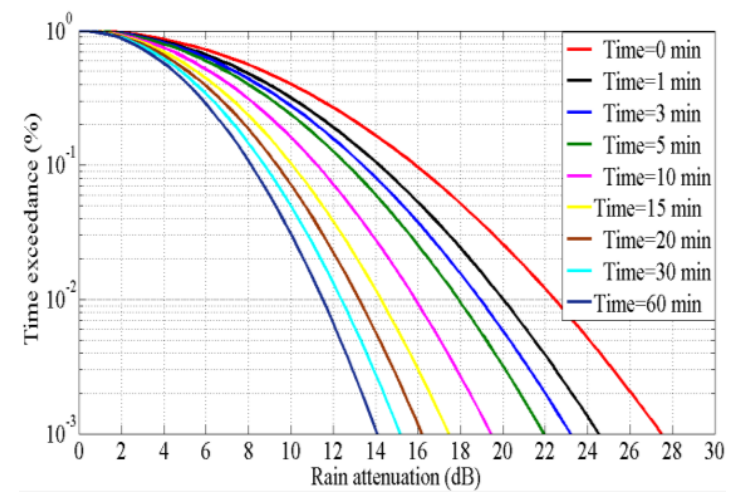

Figure 2. Measured rain attenuation at Penang Malaysia for the year 2008 and complementary cumulative distributions of rain attenuation for several time delays

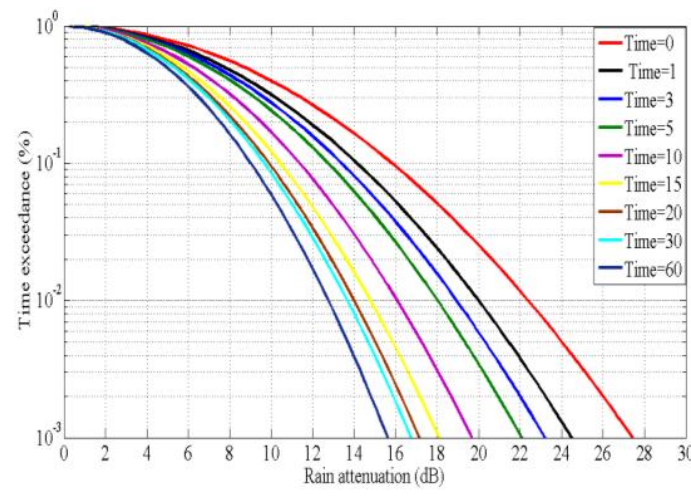

Figure 3. Measured rain attenuation at Penang Malaysia for the year 2009 and complementary cumulative distributions of rain attenuation for several time delays

Every curve corresponds to a specific time delay, while the red curve represents measured rain attenuation distribution before applying the time diversity technique. It is clear that there is an inverse relationship between the time delay and the level of attenuation exceeded for a given time percentage. For illustration, at 0.01 time percentage of , the rain attenuation level without applying time diversity technique is $22.4 \mathrm{~dB}$ while, the rain attenuation level values are $20,19,17.8,15.8,14.3,13.1,12.3$ and $11.5 \mathrm{~dB}$ with time diversity for time delays of $1,3,5,10,15,20,30$ and 60 min respectively.

\section{TIME DIVERSITY GAIN ANALYSIS}

Time diversity gain refers to the difference between the attenuation levels of two versions of a received signal, separated by a time delay, at the same percentage of the total time. Thus, time diversity gain GTD is a function of the attenuation level $\mathrm{A}$ as well as the attenuation level with time delay $\delta$ t. According to Equation (4), Figure 4 and Figure 5 depict the diversity gain in attenuation exceeded for a fixed percentage of time. For example, at 0.01 time percentage, the diversity gain when applying time diversity technique is 2.3 , $3.6,4.78,6.6,8.21,9.1,10.1$ and $10.85 \mathrm{~dB}$ for time delays of $1,3,5,10,15,20,30$ and 60 min respectively.

It is clear that the gain increases for decreasing value of time percentage of rain attenuation. This goes back to a well-known fact that heavy rain events tends to be in a short time as compared to light rain events. This gives a very clear understanding of how to improve performance of mitigation techniques.

Figure 4 and Figure 5 represent time diversity gain as a function of time delay, $\delta$ t. The first note worthy result is that the diversity gain increases with the increase in the value of time delay and rain attenuation, A without diversity. In addition, the most important observation is that the diversity gain increases rapidly as a function of time delay up to $20 \mathrm{~min}$. This looks sensible because the most of the rainfall in tropical regions is characterized with short time period and high intensity. The increase tends to be slight for time delay of more than $20 \mathrm{~min}$. Table 1 shows time diversity gain at $0.1 \%$ and $0.01 \%$ for 2008 and 2009 . It is clear that the gain increases for increase time delay. 


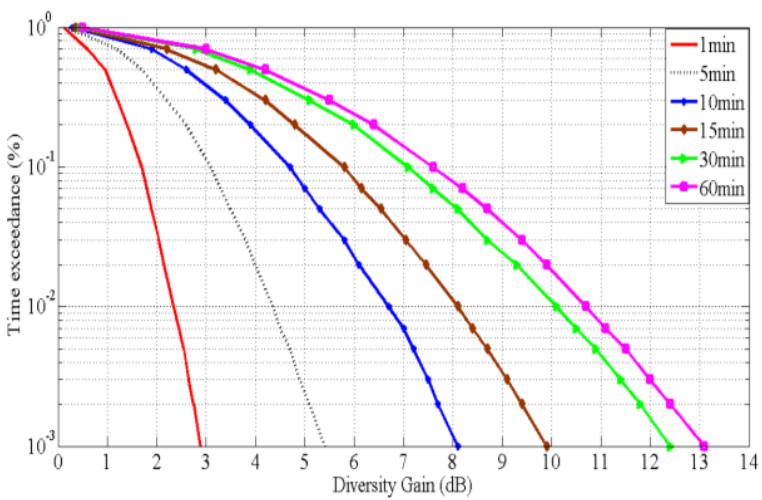

Figure 4. Complementary cumulative distributions of measured time diversity gain of 2008 for several time delays

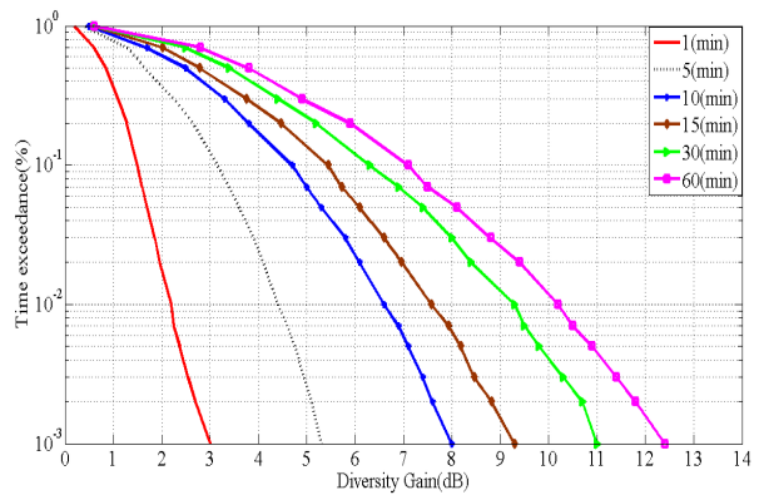

Figure 5. Complementary cumulative distributions of measured time diversity gain of 2009 for several time delays

Table 1. Time Diversity Gain

\begin{tabular}{|c|c|c|c|c|c|c|}
\hline \multirow[t]{3}{*}{$\Delta \mathrm{t}, \min$} & \multicolumn{6}{|c|}{$\mathrm{G}_{\mathrm{TD}}$} \\
\hline & \multicolumn{2}{|c|}{$0.1 \%$} & \multicolumn{2}{|c|}{$0.01 \%$} & \multicolumn{2}{|c|}{$0.001 \%$} \\
\hline & 2008 & 2009 & 2008 & 2009 & 2008 & 2009 \\
\hline 1 & 1.71 & 1.5 & 2.33 & 2.17 & 2.87 & 3 \\
\hline 5 & 3.1 & 3.13 & 4.33 & 4.42 & 5.38 & 5.3 \\
\hline 10 & 4.67 & 4.67 & 6.67 & 6.58 & 8.13 & 8 \\
\hline 15 & 5.83 & 5.46 & 8.13 & 7.58 & 9.88 & 9.3 \\
\hline 30 & 7.1 & 6.33 & 10.13 & 9.29 & 12.38 & 11 \\
\hline 60 & 7.63 & 7.1 & 10.67 & 10.21 & 13.08 & 12.4 \\
\hline
\end{tabular}

\section{CONCLUSION}

Rain attenuation along earth-to-satellite link were measured for one-year period at $12.225 \mathrm{GHz}$ in Malaysia. The time diversity mitigation technique was applied on measured rain fade to investigate the improvement in system. Time diversity gain was also estimated from measured one-minute rain attenuation for one year period as a function of rain attenuation levels and time delay. More than $6 \mathrm{~dB}$ and $8 \mathrm{~dB}$ gain were observed at $0.1 \%$ and $0.01 \%$ outages for 10 minutes delay time. This finding will be very useful for earth-to-satellite link designers to improve reliability by applying time diversity as a rain fade mitigation technique.

\section{ACKNOWLEDGEMENTS}

Authors are grateful to Research Management Centre, International Islamic University Malaysia to support this research through research grant RIGS16-065-0229.

\section{REFERENCES}

[1] Nomoto T, "Toward the realization of a 21-GHz-band satellite broadcasting system”, Broadcast Technol., 2004, 20, pp. 7-11.

[2] Lwas AK, Islam MR, Habaebi MH, Mandeep SJ, Ismail AF, Zyoud A, "Effects of wind velocity on slant path rainattenuation for satellite application in Malaysia", Acta Astronautica, 2015 Dec 31, 117, pp. 402-407.

[3] Pan QW, Allnutt JE, Tsui C, "Evaluation of diversity and power control techniques for satellite communication systems in tropical and equatorial rain climates", IEEE Transactions on Antennas and Propagation, 2008 Oct, vol. 56, no. 10, pp. 3293-3301.

[4] Rafiqul IM, Habaebi MH, Haidar IM, Lwas AK, Zyoud A, Singh M, "Rain fade mitigation on earth-to-satellite microwave links using site diversity", In Communications (MICC), 2015 IEEE 12th Malaysia International Conference on 2015 Nov 23 (pp. 186-191). IEEE.

[5] Rafiqul IM, Muhammad N, Singh M, Lwas AK, Adawiyah R, Ismail A, "Analysis of Rain Fade Mitigation Using Site Diversity on Earth-toSatellite Microwave links at Ku-Band", 5th Brunei International Conference on Engineering and Technology (BICET 2014), IET, 2014.

[6] Islam Md. Rafiqul, Ali Kadhim Lwas, Mohamed Hadi Habaebi, "Site diversity gain for earth-to-satellite links using rain intensity measurement", Indonesian Journal of Electrical Engineering and Informatics (IJEEI), vol. 5, no. 4, pp. 330-338, ISSN 2089-3272, 2017. 
[7] Ulaganathen K, Rahman TA, Islam MR, Malek NA, "Mitigation technique for rain fade using frequency diversity method", Int. Communications (MICC), 2015 IEEE 12th Malaysia International Conference on 2015 Nov 23 (pp. 82-86), IEEE.

[8] Ismail AF, Watson PA. Characteristics of fading and fade countermeasures on a satellite-Earth link operating in an equatorial climate, with reference to broadcast applications. IEEE Proceedings-Microwaves, Antennas and Propagation. 2000 Oct;147(5):369-73, DOI:10.1049/ipmap:2000074.

[9] Matricciani E. Time diversity as a rain attenuation countermeasure in satellite links in the 10-100 GHz frequency bands. In2006 First European Conference on Antennas and Propagation 2006 Nov 6 (pp. 1-6). IEEE, DOI:10.1109/EUCAP.2006.4584760.

[10] Arapoglou PD, Panagopoulos AD, Cottis PG. An analytical prediction model of time diversity performance for earth-space fade mitigation. International Journal of Antennas and Propagation. 2008 Mar 23;2008, DOI:10.1155/2008/142497.

[11] Fabbro V, Castanet L, Croce S, Riva C. Characterization and modelling of time diversity statistics for satellite communications from 12 to $50 \mathrm{GHz}$. International Journal of Satellite Communications and Networking. 2009 Mar 1;27(2):87-101, DOI: $10.1002 /$ sat.927.

[12] Kourogiorgas CI, Panagopoulos AD, Livieratos SN, Chatzarakis GE. On the outage probability prediction of time diversity scheme in broadband satellite communication systems. Progress In Electromagnetics Research $C$. 2013;44:175-84. DOI:10.2528/PIERC13082704. 